\title{
The Nature of Host Community Participation in Informative Consultation and Decision-Making Processes in Tourism Development: A Case Study of Umhlwazini, Bergville, KwaZulu-Natal
}

\author{
Nduduzo Ngxongo, ${ }^{*}$ Nsizwazikhona Chili \\ Durban University of Technology, South Africa \\ ngxongonduduzo@gmail.co, ${ }^{*}$ nsizwazikhonac@dut.ac.za
}

\begin{abstract}
Tourism industry in the central Drakensberg region has enjoyed a noteworthy growth in visitor influx and earnings as well. Conversely, poverty and poor living conditions in and around villages positioned nearby to major tourist destinations in the country continues to degenerate, which ultimately raised the issue regarding the contribution of host communities in tourism decision making and informative consultation processes. Community consultation and participation in decision making processes constitute a crucial component that offers assurance to the host community that tourism benefits will be shared with the community and that their views will be considered when making tourism decisions. Thus, this paper aims at exploring the existing extent of community consultation and participation in tourism decisions making, using a case study of Umhlwazini, Bergville, KwaZulu-Natal. The study incorporates a qualitative research approach with the use of interviews, focus groups and observations. The research findings show that the informative consultation process of community in the study area has been centralised, controlled, and minimal to none regardless of the constant aspirations of the host community to participate in decision making processes. Agreements and decisions relating to tourism and the community resources are agreed upon by outsiders who have no interest of the community at heart. The study recommends a private-public partnership, financial support for small local business enterprises, policy development and amendment to promote active community participation in tourism consultation and decision-making processes. This study contributes to a broader context of community participation in decision making structures, and present scholarly significance to researchers, students and academicians, and theoretical value to government, policy makers, investors and tourism authorities.
\end{abstract}

Keywords: Consultation, community participation, decision-making processes, host community, tourism, development

\section{Introduction}

Tourism is progressively developing into a central economic zone within the Drakensberg region. The industry of tourism is said to represent one of the most valuable sectors in the self-sustainability of UKhahlamba region, particularly the central part of the mountain because of its distinctiveness appearance (UKhahlamba Local Municipality, 2016). Consequently, the industry signifies one of the prime sources of livelihood, employment opportunities and infrastructural development for many countries, communities and tourist destinations (Baral and Heinen, 2007).The participation of local communities, particularly in tourism consultation and decision making processes cannot under any circumstances be ignored as it constitutes a critical component of tourism development. Ngxongo (2016) in his study of community participation and tourism development in Bergville discovered that the level of participation in extremely poor hence this study is essential in bringing to light the existing community consultation practise in Umhlwazini area.

According to World Tourism Organisation (WTO) the central constituent players of the industry, which are the government (public), investors (private), and host communities; are ought to work together as a foundation for a successful development of the industry particularly in grassroots level. The inability to realise the need to integrate the interests of all role players generally lead to exclusion, marginalisation, power struggle and passive participation of locals in tourism activities. In essence, this suggests that there is a communication breakdown between tourism stakeholders which results in uncertainty and volatility. Historically the local community of Umhlwazini has always been on the receiving end as most tourism investors often eliminate and exclude the views and the interest of the host community. Accordingly, the effect of poor consultation and participation of host communities in tourism activities constitutes one of the major challenges facing the tourism industry globally. The notion of decision-making participation and informative consultation of the host community remains the most appropriate and effective methods of dynamic community participation(Cole, 2006; Tosun, 2006; Murphree,2009; and Ngxongo, 
2016).Subsequently, this study focuses on investigating the present consultation processes of the host community in matters affecting tourism at Umhlwazini. The study further examines the impact of poor consultation of local communities in tourism activities.

Scheyvens (2002) defines community consultation in the context of tourism as a process through which the adjacent citizens from where the tourist destination in situated are given sufficient right to voice out their opinions about the progression of tourism, they are consulted when major decisions are taken, and they are constantly updated on issues relating to tourism. Tosun (2000) further suggests that the host community in tourism development can participate by means of various methods, and two different levels of influence, in identifying community needs, offering resolution, preparation of new programmes and circulation of benefits. Ineffective consultation of the community poses a number of negative impacts which are not favourable to the enhancement of both the industry and the host communities. Various research scholars (Ashley, 2000; Li, 2006 and Lepp, 2008, and Ngxongo, 2016) correspond that the participation of the host community in tourism activities is mostly reliant on how crucial information is filtered from the top management (authorities) to the bottom level (community), thus the indispensable function of consultation can never be disregarded. On the basis of the above stated phenomenon, the study of this nature is mainly significant in the local environment for the reason that it contributes to theories in relation to why specific groups of community members participate in tourism, and some don't and also the modern nature of community consultation as far as making tourism decisions is concerned. The study allows for a foundation for the development and implementation of innovative policies and guiding principle on the community consultation and decision-making processes in the UKhahlamba municipality and to the entire region of the Drakensberg. As such, anticipated policies are to be utilised in educating the host community of Umhlwazini about tourism, to encourage maximum participation of the community in the early stages of development, and to track the development of the programme.

The outcome from this research also extends the body of knowledge about the impediments and key success factors regarding community consultation and decision making processes in tourism development in KwaZulu-Natal. Wider and deeper understanding of barriers to community participation will assist tourism policy makers to initiate appropriate strategies to overcome those limitations. Ultimately, the study helps to establish a level of tourism understanding and awareness among tourism authorities in Umhlwazini and the local community in particular. Such understanding can lead to better community participation and tourism benefits. In the present day, governments, including tourism authorities and the private sector have accepted the theoretical necessity to afford some level of authority and control of natural resources to the host communities; but the practicality of this concept remains a daydream misinformation as the majority of local communities are by no means consulted during the planning and budgeting stages which forms a crucial component of decision-making processes. Participation in tourism requires partnership and the dedication so to guarantee sustainability of tourism development activities. The impacts of participation are generally an indication of a particular stage of role players' involvement in the decision-making processes which as a result allows community members to make knowledgeable promises to a particular initiative (Stronza and Gordillo, 2008). The latest uproar of radical economic transformation in South Africa, which recognises the need to give a portion of powers to local communities, presents a great prospect for the tourism industry to explore the present nature and the extent to which host communities participate in decision making processes regarding tourism activities.

\section{Community Involvement Concept in Tourism Decision making Processes}

A number of research scholars (Tosun, 2000: Chok and Macbeth, 2007; Zhao and Ritchie, 2007; and Ngxongo, 2016) have simultaneously concurred that "the notion of community participation in tourism can be evaluated through two methods; decision making process and sharing of benefits with the host community". The United Nations Economic and Social Council Resolution 1929 (LVIII) illustrate the idea of involvement in development in the framework of tourism as follows: the privileges to voice out opinions on the proposed development, evenly and fair dealing with sharing of the benefits of tourism, and allowing the host community to participate in decision making and the implementation of the development or program. The underlying concept of allowing the host community to partake on development issues relating to tourism is to grant them the opportunity to utter their concerns, suggestion and get the necessary answers in relation to 
the development (Tosun, 2000). Simultaneously the community forms part of the decision making structure which makes it simple to distribute benefits generated from tourism in the area for to all the interested and affected parties, including the community. Equally, Cole (2006) coincide with the aforesaid analysis that the host communities can contribute in tourism campaigns and programs during all important phases of development including groundwork, implementation and sharing of benefits. Community involvement is ought to start in the early phases of development in tourism so that are role players will understand the responsibilities and expectations. The host community participation in this critical stage of the development can be in a form of providing manpower, sharing their profound enriching knowledge with the investors, providing materials and protecting their interest through discussions and signing of agreements. Tourism benefits' sharing represents an inclusive partnership between role players as it suggests that the host communities are able to enjoy economic remuneration, infrastructural development from the development of the tourism industry (Manyara and Jones, 2007).

A clear and honest method is particularly necessary for an effective community participation and consultation in tourism. Community meetings, written consultations and awareness campaign can be particularly useful for investors to gain support from the wider spectrum of the community. This way, the host community will feel connected to the development, and they will appreciate that their views are taken seriously. It is only when the host community benefits financially and their opinions are respected that their contribution to tourism development will become noteworthy of them. Community involvement in tourism is a great weapon that investors can use to win the support of the locals while guaranteeing the safety of the clients. When the people see themselves as part of the bigger picture; they will make sure that they do not engage in any violent situation that can taint their involvement in tourism. This can include protecting tourists against local crime and treating them with respect and dignity (Okazaki, 2008). This idea is also entrenched in the World Tourism Organisation principles, which categorically state that the host communities should and must at all time be consulted and participate in decision-making as they represent a fundamental component of tourism development (Chok and Macbeth, 2007)

Community Involvement in Benefit-Sharing: The idea of distribution of tourism benefits evenly with local communities has always been seen as one of many methods of community participation in the industry of tourism (Tosun, 2000; Li, 2006). Successful tourism development needs enhanced collaboration among tourism role players, including the industry, government at all levels, local communities, and tourism authorities. Benefit sharing is an important controlling instrument to consider in encouraging participants in particular the community (Eagles, McCoo and Hynes, 2002). Community participation has long been accepted as an instrument for harmonising power in spreading the benefits of development projects. In a top down development situation, the sharing of benefits is a way to pave the way for community participation in decision-making. In the absence of an effective analysis of the local political and development environments, it is difficult to conclude whether or not community participation in decision making is likely to be effective at a destination. Several studies and numerous worldwide development agencies have recognized that tourism is an influential tool for community enhancement due to the fact that it is an important economic sector in most countries (Chok and Macbeth, 2007; Zhao and Ritchie, 2007). Though there is no standard technique for assessing the sufficiency of community participation levels (Li, 2006). Communities can be attracted to participate in tourism through sharing the benefits acquired from tourism with them, and one requirement for a successful community tourism program, according to Scheyvens (2011) is that balanced profits of tourism "must remain in the hands of the majority of community members in an uncluttered and straightforwardly understood manner". An example of community participation in the benefits of tourism can be seen at the Isimangaliso Wetland Park, especially through its community outreach program, Isimangaliso's Arts and Crafts. The park provides an ideal platform for the local women to sell their products to the visiting tourists. The total proceeds from the project directly go to the community members that are involved in the arts and craft project. This is one of the strategies that are adapted by the park as an effort to enhance the footprint of the host community in tourism activities through arts and crafts (Gumede, 2009).

Study Area Community Consultation Processes: The UKhahlamba local municipality concedes the actuality that almost every one of the major tourism destinations in the Drakensbergis situated within local communities and predominantly exist side-by-side with the host communities. Many of these destinations are the main source of survival while others have a profound spiritual history of the host community. Hence, the 
IDP policies do not only reiterate the need to incorporate the host communities of Bergville when making decisions about tourism destinations, but also emphasises the importance of sharing the tourism benefits with the surrounding communities in which all form part of community consultation procedures (UKhahlamba Local Municipality IDP, 2016). Regrettably, the IDP policies do not specify the necessary steps that must be followed in the community to be role players in tourism and to what extent can they play a part in making decisions. Hence the tourism authorities together with the private sector are taking advantage of this unawareness as a result the host community continues to be spectators in their own area. According to Ngxongo (2016), in Umhlwazini community the practise of community participation in decision making of tourism activities is practically non-existent which has yielded negative effects in the past. Community consultation in Umhlwazini is merely limited to issues in relation to livestock grazing, but when it comes to tourism issues; community consultation remains a top-down approach where all decisions are agreed upon without the input of the host community.

Community awareness, meetings are globally recognised as some of the most successful methods of consulting communities on issues that directly affect them (Tosun, 2006). The absence of community meetings contributes largely to the exclusion of the host communities as the majority of decisions are deliberated on community gatherings. Community meetings in the context of tourism serve to enlighten the locals about the details of all tourism programs, how can they participate and how these programs will affect the area economically and environmentally. Host community members are to be expected to have a clearer viewpoint on real issues if they are honestly consulted. This is in contrast with the state of affairs at Umhlwazini as according to Ngxongo (2016) the tourism issues of the village are certainly not discussed in community meetings which suggest that the community is deliberately excluded from making comments. Moreover, the community members rely on hearing says and rumour mill for information as there is a noticeable gap between the management of the resort and the community.

The Impact of Ineffective Community Consultation in Tourism: The consultation of the host community is fundamental, and authentic community involvement in decision making processes can uplift community awareness (Tosun, 2000). If the host community is actively involved in the process of developing tourism; it is most likely to support local tourism initiatives, actively participate in tourism, protect and safeguard visitors against any form of criminal activities arising within the community. Unfortunately, poor consultation with the host communities in tourism remains one of the foremost challenges that continue to undermine the constitutional rights and the desires of the host communities to participate in tourism activities (Mitchell and Ashley, 2010). Poor consultation of the host communities prevents the locals from participating in decision making processes (Cole, 2006). Consequently, the negative impacts of ineffective consultation between the community and tourism authorities have yielded harmful outcome, i.e. apathy, hostility towards visitors and negative outlook towards tourism which ultimately emerges as counteract to tourism development and community fulfilment. Effective, genuine and constant community consultation is particularly paramount in an effort to sustain the host community interests, values and their will to participate in tourism activities \& beyond. The tourism industry has to do the utmost to incorporate and look after the interest of the host communities in developing the global agenda of the World Tourism Organisation. The present conditions of corruption, monopolisation, and deliberate exclusion of communities in decision making structures should be erased and undermined. Instead, inclusive management of tourism destinations should be encouraged, sharing of benefits with the community should be promoted and development must take place with the host community approval at all times.

\section{Methodology}

Research Design: According to Burns and Grove (2003) research design is an in depth outline for conducting a research study with control over elements that may interfere with the legitimacy of the findings. The study is descriptive in nature; with the use of qualitative research design. The qualitative aspect of the study aspires to gather an in-depth understanding of community behavior towards tourism issues and the grounds that leads to such behavior. This particular study investigates the "why" and "how" of consultation and decision making processes. Mainly, qualitative research allows the principal researcher to interact openly with the participants, offering the opportunity for comprehensive assessment of the matters and the generation of thorough responses (Nykiel, 2007). This research approach is mainly suitable in a study of this nature since it 
offers a holistic outlook of the local community of Umhlwazini with regards to consultation processes and their participation in community project decision making bodies.

Sampling method: The purposive sampling is utilized as it is the most suitable for this study because of its cost effectiveness; the researcher can identify participants who are likely to provide data that are detailed and relevant to the research question. According to Bryman (2008) purposive sampling is a form of nonprobability sampling in which decisions concerning the individuals to be included in the sample are taken by the researcher, based upon a variety of criteria which may include specialist knowledge of the research issue, or capacity and willingness to participate in the research.

Study Sample: A total number of 25 respondents make up the study sample; the selected respondents represent the host community, tourism authority (Didima Resort and Ezemvelo KwaZulu-Natal), community Leadership (traditional council). The research study was undertaken in a recognised area in KwaZulu-Natal Province. The researcher found the participants in these areas to be directly involved or who may have had experience with this issue.

Data collection: A singular form of data collection was used; the researcher opted to exploit an unstructured interview method with open-ended questions for data collection. The interviews were conducted in a form of one-on-one sitting with all the respondents; a voice recorder was used to record all the interviews. Each interview lasted approximately 40 minutes. The interviews were conducted in the isiZulu language so that the respondents could have a clear understanding of the questions. The interviews covered all the necessary community structures including, the leadership, community members, traditional leaders, resort management and local tourism authorities. A total of twenty-five (25) interviews with the respondents were conducted so as to solicit all the necessary information that was required to get the appropriate answers. Two (2) focus groups were also interviewed as they are useful to obtain detailed information about personal and group feelings, perceptions and opinions, they save time and money compared to individual interviews and they provide a broader range of information.

Data analysis: This study adopted a thematic data analysis method, the information collected through interviews using voice recorder was translated, edited and transferred into a hard-copy format, the information was then coded per objective and categorised accordingly. Welman, Kruger and Mitchell, (2006) state that field notes can be described as detailed notes made by hand, tape recordings and observations that are compiled during qualitative interviewing. The results were consequently interpreted in parallel with the literature review and discussed.

Study Area: The Umhlwazini Village is a well-known rural village positioned adjacent to Didima Resort, falling within the authority of the UKhahlamba local municipality and the larger UThukela District Municipality. The village is placed about 6.2 kilometres from the southern section of the Didima Resort, and suitably situated on the way to all attractions that are available in the area. According to UKhahlamba Integrated Development Plan (2011) tourism and livestock business are the two major financial sources of live hood for many community members. 


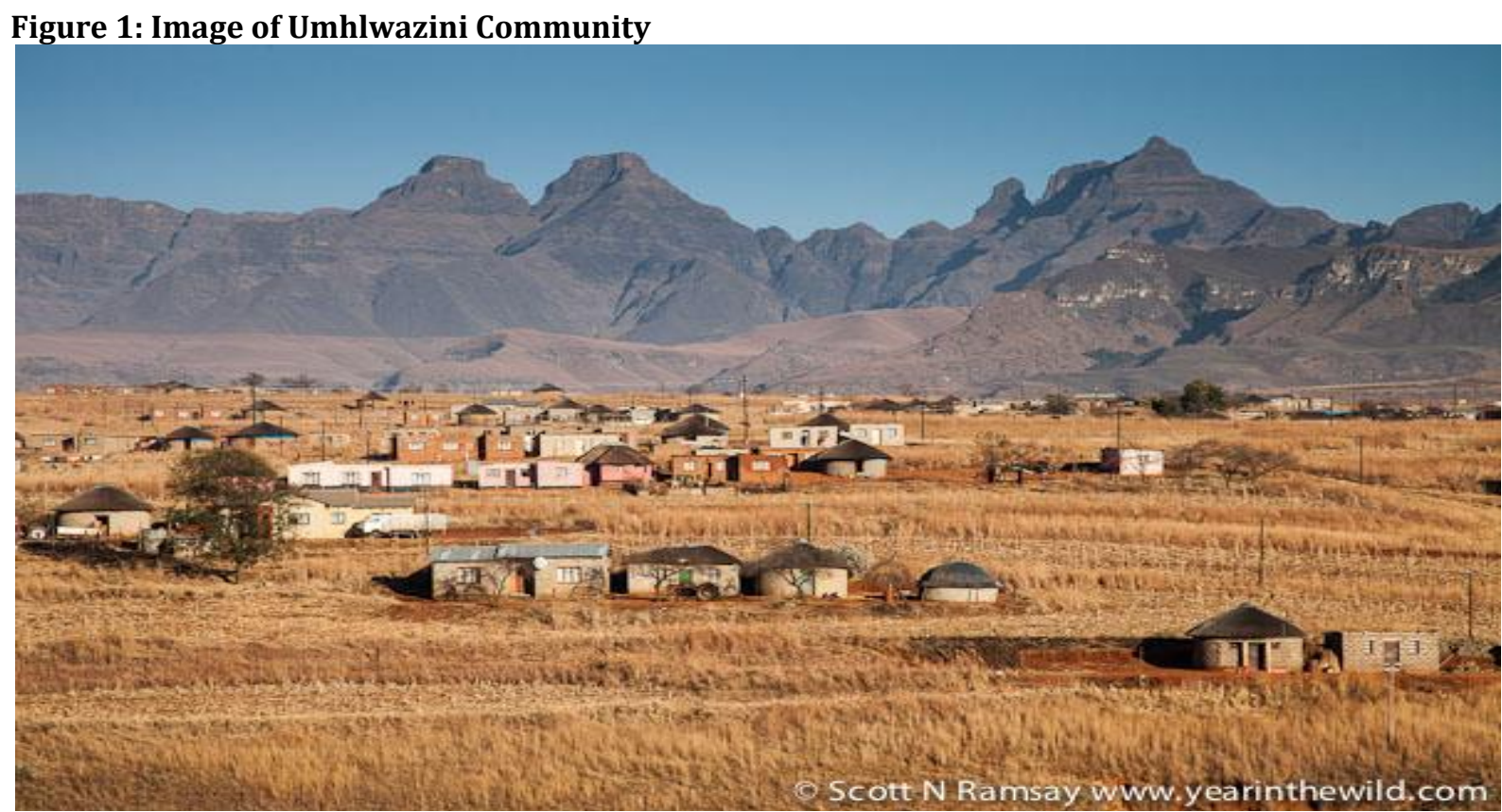

Source: Scott (2013)

The village is set on the banks of major tourism features of the Drakensberg including the famous Mikes Pass, cathedral peak, San paintings and the mountain peak of snow. Hence this village is a famous stop for many visitors who are flocking to the either the resort or cathedral park hotel. The town of Bergville is the main administrative centre of Umhlwazini village; the area is under the administration of Amangwane Traditional Council (ATC). The host community of the village is a component of the surroundings and tourism facilities in the area. Umhlwazini community is a village mainly occupied by rural commune directly linked with the citizens that were removed from where Didima Resort is located (UKhahlamba Integrated Development Plan, 2011).

\section{Data Analysis and Presentation}

This section presents the responses from the interviews conducted from the focus groups and unstructured interviews. The data are presented in numbers and percentages, the results discussed and the data presented in this section are explicitly from the respondents. The themes that are identified for the purposes of data analysis are; the scope and nature of informative consultation and decision making processes, community participation strategy, impediments to active participation in decision making, and community structures that are involved in decision making. This primary objective was to explore the existing extent of community consultation and participation in tourism decisions making, using a case study of Umhlwazini, Bergville, KwaZulu-Natal. The results indicate that $72 \%$ of respondents are male, while $28 \%$ are female. This uneven proportion in respondents' gender is possibly caused by the fact that Umhlwazini is a profound rural village, as such, the belief in most villages is that the men knows better and should at all time be in charge or be the leader rather than a women hence the majority of respondents were male. The entire respondents, $100 \%$ was directly and indirectly involved with tourism activities in the area. Correspondingly, all of the respondents were residing in Umhlwazini area which was an advantage for the study since all respondents were familiar with the study area circumstances. Of all the respondents, $52 \%$ represented the host community members while $32 \%$ of the respondents represented the Amangwane Traditional Council whereas $12 \%$ of the respondents represented Didima Resort, and 4\% respondent represented Ezemvelo KwaZulu-Natal.

Level of Community Consultation and Decision-making Procedures: In an effort to gain further information on the level of community participation in tourism development in Umhlwazini community, the respondents were probed on their participation in tourism decision-making procedures. The majority of the respondents indicated that they had never been part of any decision making process neither they have been 
called to comment or make any form of suggestion. Of the 25 respondents that were selected for the study, a total of $28 \%$ of the participants indicated that they have previously been part of the decision making process about tourism, whereas the majority $72 \%$ of the respondents indicated that they have never participated in tourism decision-making processes. In addition, $84 \%$ of respondents indicated that tourism authorities in the area have done very little to engage the community in the decision making of tourism activities. In essence, this research discovered that the host community of Umhlwazini area is mostly left over-looked in decision making processes and the information about tourism issues is always vehemently filtered down to the people. The respondents were subsequently asked whether if they had ever been requested to comment, suggest or recommend something about tourism at Umhlwazini; the majority of the respondents, $76 \%$ of the respondents indicated that they have never been requested to comment or suggest anything about tourism at Umhlwazini or Didima Resort, whereas $24 \%$ of the respondents indicated that they have once or twice been requested to comment and pass remarks about tourism in the study area. The ordinary members of the community are generally excluded when decisions about tourism are taken, as the small portion of the respondents that have previously been asked to participate in decision-making were from Didima Resort, ATC and the community councillor and none of the community. The informative consultation of the host community members as far as tourism development is a concern in the area remains deprived, largely, due to the disregard of community participation by tourism authorities.

The respondents were also asked whether they would wish to participate or be consulted when tourism decisions are finalised. The outcome of the investigation indicates that all the respondents unanimously agreed that they would be satisfied if the community was involved and consulted when decisions are taken as they are also custodians of the area where tourism is happening. According to the community of Umhlwazini, participating in tourism decision making is very important for them as their hopes for a healthier tomorrow are largely dependent on tourism, hence they need to be more involved than ever before. Regarding the decision-making processes, when the respondents were asked about their level of participation in decision making, one interviewee expressed the following:

"The community has no voice in tourism matters, in some cases they do not even engage us in issues relating to community projects; they will just come with a full plan on how everything will be executed, how much will be spent and who will do what and when. We hardly express our opinions on tourism yet the land belongs to our forefathers"

Taking into account the study outcomes, the decision making procedures of Umhlwazini tourism development remain very much monopolised and exclusive, community participation levels remains rather minimal which, in turn, functions against the principle of inclusive development in tourism (Cole, 2006). The rationale for such a restricted decision making process is that tourism in the region remains the key source of economy, hence Ezemvelo KwaZulu-Natal Wildlife is not willing to bestow the powers to people that possibly can make a decision against the will of the organisation. The findings of this study in this regard are not parallel with the principles of the World Tourism Organisation (WTC); which declares that host communities in areas where tourism is taking place have to at all times be a component of every level of management. The World Tourism Organisation during (World Tourism Day (WTD), 2014) reiterated the role of tourism in promoting the spirit of active participation of local communities using community development programs. A special emphasis was dedicated to host communities with a focal point on how the tourism industry can be exploited in advancing community participation interest in decision making processes, particularly from the community members on the ground. The WTD recognises that host communities have the rights to actively participate efficiently in the day to day administration of tourism matters occurring in their area. Consequently, mutual agreements must be reached that recognises the notion that community based tourism activities are must at all times involve community members in decision making procedures as per the host community desires and priorities.

Tosun (2000) asserted that community participation in tourism can take place in two forms; through the decision-making process and through sharing of tourism benefits with the host community. However, the outcomes of this study suggest that none of the two methods suggested by Tosun (2000) is happening at Umhlwazini as the community vehemently denies any involvement in consultation and decision making processes in their area. The results above indicate that the community of Umhlwazini is again being excluded in one of the most effective and common techniques of encompassing the element of local community in 
tourism development. The overall level of community participation in decision making of tourism development at Umhlwazini is extremely low. The members of the community are not involved in any of the tourism project initial stages, the views and opinions of the community about any proposed projects are not taken into consideration. This all suggests that the level of community participation in tourism is very marginal and selective hence the level of participation is very low.

Community Participation Strategy: The participants were also asked about the existing strategy that is used to promote maximum participation of the host community in tourism. The official custodian of tourism industry in the region is Ezemvelo KwaZulu-Natal Wildlife (EKZNW) in corporation with UKhahlamba Local Municipality. The study discovered that the present strategy that is used in the area is a top-down participation approach where community members are informed about tourism development activities rather than being engaged. There were various flaws that were discovered during the interviews, including the fact that community leaders are not considered as the role players in the decision making structures of tourism in the area. At least $86 \%$ of the respondents indicated that the existing participation strategy is was not drafted for the best interest of the community as it gives no power to the people to make meaningful decisions about tourism, whereas the other $14 \%$ indicated that there is a serious need for amendment of the strategy so that it serve the community rather than government. In theory, the tourism authorities in the area do concede the requirement to engage community members in decision making processes, but in practical sense; it's not yet taking place. When respondents were asked about this issue, one interviewee expresses the following response;

"I think the biggest problem with these people (EKZNW) is that that is they do not respect the community, all our opinions are not important to them. The system that they are using on us is more like that of apartheid where you are always told what to do and how you must do it".

Conflict of priorities between the community and EKZNW was also discovered to be one of the main issues that deteriorate the effectiveness of the participation strategy. Tourism is not the priority of EKZNW at any level. According to the outcome; tourism authorities from EKZNW declared that the main priority of the organisation is "CONVERSATION", and not tourism. This however was against the priorities of the people as the host community recognises tourism as their main source of revenue. The focal point of the participation strategy is conversation, and that is attested by a number of conservation community programs that were introduced, including; fire fighting initiative, community livestock program and landscape protection programs. These programs and others of similar nature are said to be the key priorities of EKZNW. A total of $92 \%$ of the respondents indicated that it's rather difficult for the community members to participate in decision making processes as most of the proposes activities are conservation related rather than tourism, whereas the other $8 \%$ of the responded indicated that they do not understand the distinction between tourism and conversation. According to Cole (2006) community participation strategy in tourism is likely to be more efficient and helpful if the host community is involved in the onset phases of the policy development as they are the ones to be affected by the strategy, they are the ones to approve and accept the strategy, and that they are the ones to champion and implement the strategy.

The results also discovered that the local municipality has no clear strategy or a policy that makes it compulsory for EKZNW to integrate community members whenever tourism decisions are taken in the area. The strategy does make provisions for the participation of host community members in EKZNW programs, but it does not specify as to how much and to what extent is the community allowed to participate. The UKhahlamba Local municipality is merely involved in the tourism affairs in the area through financial support thus all decisions about tourism activities in the area are decided by EKZNW single-handedly. The overall outcome of the study as far as participation strategy indicates that the strategy is manipulative, it is designed in such a style that the community members of Umhlwazini are excluded from voicing out their opinions and that there are too many flaws within the strategy that makes it exceptionally trouble-free for organisation like EKZNW to take advantage of the community.

Community Representation in Decision Making Structures: Tourism decisions are generally taken from structures or a board that represent the interests and the beliefs of all role players. The main role players in tourism, particularly in rural tourism and Community Based Tourism (CBT) are the community, government and investors. This paper furthermore looks at the extent to which the host community represented in the 
structures that makes decisions about the direction of tourism at Umhlwazini. On the topic of community representation, the study discovered that in theory the community should be represented by two committees that were elected the people. The first committee was elected with the responsibility to oversee tourism issues in the area, whereas the other committee was elected with the responsibility to represent the traditional council. In practise though, these two committees are never invited in any of the meetings, and that is due to disregard of community capacity to make competent decisions by authorities. A memorandum of understanding was mutual adopted in 2013 between the community and EKZNW that declared that host community members are ought to be allowed to express their grievances and remarks on how their land must be used, but none of the agreements have come into full effect.

According to Phillips and Roberts (2013) community structures and leadership are contributing dynamic to the success of tourism programs, especially in rural communities where illiteracy levels are relatively high. This is achieved by allowing the democratically elected community structures to be part of the decisionmaking processes in tourism development activities. The findings of the study are in contrast to the abovementioned analysis as $72 \%$ of the respondents indicated that as officially elected community members generally they are never invited to participate in any of the decision making meetings by the authorities, the other $28 \%$ remained neutral as they were not in any leadership position to comment. The outcome of the study also discovered that the community levy fund, which is meant to support the community remains undisclosed as even the leaders of the community are not fully clued up about how much precisely is the community expected to get and how does one qualify to get the funding. According to Tosun (2000) the notion of sharing the tourism benefits with the community begins with a decision on how much benefit is to be given to the local community and that decision must be taken by the tourism authorities jointly with community leaders and community representatives. The traditional king and the community councillor are the only two people from the community who are occasionally invited during meetings. Regrettably, they are made to adopt a guest role and not participate in discussions about issues that are affecting the tourism patterns of their community. The results suggest that the community members of Umhlwazini are either deliberately excluded or the apparent lack of interest from the community could be the underlying basis for their exclusion, either way this phenomena present a challenge that can generate further detrimental problems in the near future unless it is appropriately and efficiently addressed by the people who are endowed with power. According to the outcome of the interviews, it can be strongly concluded that the host community of Umhlwazini is not represented in any of the official structures that makes final decisions about tourism development.

Impediments to Active Involvement in Tourism Decision-Making Procedures: In many developing countries, the development of the tourism industry is generally funded and controlled by international organisations that usually have incredibly little value for the host community and economic conditions of the area (Timothy, Ioannidas, Apostolopoulos and Gayle, 2002). This is because of the fact that a lot of unique tourism destinations are situated in rural and remote regions where levels of education and financial independence are extremely poor. In fact, many decisions in relation to the local tourism issues are decided somewhere else by foreign investors who have absolutely no regards to the interests and the well being of host communities where tourism activities are occurring (Wilkinson (1987). As such, in circumstances where all the authority over the management and development of tourism destinations are bestowed to private companies' only, minimal participation of community members in decision making processes is ought to happen. These, however pose a range of challenges to community members who wish to partake on tourism issues. Tosun (2000) categorised these challenges into three segments; operational limitations, structural limitations and, cultural limitations. In the quest of determining the challenges that prevents the host community to participate in decision making processes, the study outcome indicated that the most prominent limitations are related to operational and structural issues. The results suggest that the existing participatory approach is excessively one-sided to even respond to community requirements as the tourism authorities of Umhlwazini seemingly are not willing to share authority with the host community members. Indeed, Tosun (2000) asserted that the reluctance of investors to share power with host community members is one of the prominent limitations under operational challenges. Aref and Redzuan (2008), in their study of barriers to community participation toward tourism development indicated that the lack of coordination between investors and the host community, and efficient management is the main limitation of community involvement in decision making processes in Iran. 
The outcome of the interviews further indicated some restrictions, which relates to structural limitations. A total of $60 \%$ of the respondents indicated poor education levels in the region as another limitation that prevents the local people from participating in decision making, whereas $26 \%$ of the respondents pointed out that economic reliance and lack of financial resources is a prominent challenge to the community of Umhlwazini particularly for those that are interested in pursuing tourism businesses, and the other $24 \%$ of the respondents indicated a lack of skills and expertise as an additional limitation that prohibits the host community to actively participate in decision making. The lack of skills in the area is directly linked to the low levels of education as these two variables are interrelated. Dogra and Gupta (2012) conducted a study on the barriers to community participation in tourism development; the outcome of the study indicated that all three forms of limitations as declared by Tosun (2000) exists in the study area, however, structural barriers were found to be the most prominent limitations that prevented the community of Sudh Mahadev to participate in tourism development. The concluding outcome of the study in this regards indicate that the greater part of Umhlwazini community simultaneously shares similar views concerning the limitations that hamper their participation in decision making processes particularly those that are related to tourism development. The remedial actions to the aforementioned challenges can only be achieved only if the participating role players work collectively and the private sector begins to recognize and respect the need to integrate host community members in all decisions pertaining to tourism development. Nonetheless, several limitations of community participation in tourism decision making processes as stated by Tosun (2000) were proven in this study, which ultimately suggests that the existing nature of community participation in Umhlwazini community is exceptionally poor.

In comparison, of the study results with other outcomes from different studies of similar nature, the findings are approximately comparable to a larger extent. The study discovered that a very small portion of the community in Umhlwazini is in fact participating in tourism decision making processes, the study also discovered that the host community members are willing to participate in tourism activities including decision making, however, the community still remains isolated and marginalised. The study further discovered that the level of participation in consultation processes concerning tourism development at Umhlwazini remains exclusive and only for the elite. The obstructions that prevent community members from participation were found to be the poor levels of education, shortage of expertise and skills, and corruption by the officials. The outcome of the study nonetheless is not so much unforeseen as the findings are in parallel with earlier research studies that explored the topic of host community participation and decision making in the tourism industry.

Michael, Mgonja and Backman (2013) conducted a study on desires of community participation in tourism development decision making process using a case study of Barabarani in Tanzania; the study was conducted in a rural area in Tanzania where tourism is the main source of sustainability for the community of Mto WA Mbu. In their findings, the host community acknowledged the necessity to be consulted at all times when tourism issues are discussed. The findings further suggested that the majority of the community members wants tourism authorities, community elected leaders and government officials to mutually make tourism decisions in consultation with community members, and that such decision must incorporate the interests of the community at heart. The study further concluded on the challenges that limited host community members to partake on decision makings, such challenges included poor leadership, insufficient knowledge and education and the arrogance of tourism authorities in the area. These results of the study that was conducted by Michael, Mgonja and Backman (2013) are fairly consistent with this study that "host communities in many developing countries are still marginalised in participating in decision making processes in tourism, particularly in rural areas where the level of education is exceptionally low".

Marzuki (2008) conducted a study on decision making and community participation using a case study of the tourism industry in Langkawi. The study argued that the host community members in the area have been afforded enough opportunities to participate in tourism decision making processes. In contrast, the findings suggest that the community members of Langkawi remain isolated and very far from the decision making structures. The outcome also suggested that the exclusion of community members in decision making processes is due to the participation strategy that was adopted by the tourism authorities that "community members can only express their concerns about tourism activities if requested and necessary". This study further concluded that there were three main issues in the study area as far as decision making participation 
was concerned. The issues discovered was insufficient information regarding the participation procedures in the decision making, limitations on the participation policies, and the apathy amongst community members. The study concluded by recommending that an innovative framework must be introduced that will guarantee community members' utmost participation in decision making in the area.

Tosun (2000) conducted a study on the limits to community participation in the tourism development process in developing countries; the variability of the decision making process in tourism development was a major component of the study. According to the study, the genuine participation of the host community in tourism can be realised in two methods; involving the community in decision making and sharing out tourism benefits with the host community. The outcome of the study concluded that many communities, particularly in developing countries are still finding it difficult to integrate the component of the local community when decisions about the direction of tourism are taken. The findings of the study were consistent with that of the aforementioned outcome as it was indicated that major limitations to community participation, especially in decision making was lack of information and awareness, centralisation of powers by tourism authorities, lack of skills and expertise, and elite dominance of the industry by those with money. The study concluded by recommending that in the future, research should focus on decentralisation of powers with a special emphasis on allowing host communities to take charge of all tourism activities in their land of birth, and that government should invest resources in community-based tourism (CBT) seeing that this is a perfect opportunity for communities to exercise their utmost authority in tourism without the interference of the private sector.

\section{Discussion and Conclusion}

This paper looked at examining the nature of community consultation and decision making processes; using Umhlwazini community as a case study. The findings suggest that the level of participation of the Umhlwazini community in decision-making is nominal to none. Virtually all the respondents agreed that the community is not involved in decision-making concerning tourism in the area. Over the past few decades the phrase "community participation" has gained increasing usage in academic literature, policy making documents and international conference papers as a key element in attempts to attain sustainable development in African countries. The issue of community participation is now an established principle when one considers issues dealing with decision-making to achieve sustainable tourism development (Shackleton, Campbell, Wollenberg and Edmunds, 2002). While several community members claimed to be aware of tourism benefits in Umhlwazini, they were quick to indicate that the community does not participate in deciding tourism matters. The majority of the respondents stated that the community is not involved in nor does it participate in decision-making relating to tourism interrelated matters. According to respondents, lack of education, corruption, political influence and accountability are the most prominent obstacles preventing the public from participating in tourism decision making processes. The literature has revealed that community participation in tourism development, especially in decision making procedures has become a vital component in several community development projects. Moreover, it has been noted that tourism is a goodplaced poverty alleviation instrument, particularly in developing countries. The more local members participate in deciding about the projects in their area the more they will feel important and part of the process. A number of inclusive community based tourismprojects must be introduces so to give consent to community members to voice out their grievances and opinions about the tourism activities in the area. Tourism development campaign have to full take account of community members in planning, deciding and executing tourism projects in order to bring about harmony, a sense of inclusion, and the spirit of contentment.

Recommendations: The study recommends a public, private and community partnership that will generate efficient community ventures endowed with necessary expertise and capacity to encourage more community members to pursue tourism businesses as a means for sustainability. Such partnerships will provide necessary guidance, training and support for locally-based tourism. Through joint venture of this type, community leadership in the form of traditional leaders and elected leaders can benefits enormously with capacity building programs, and leadership skills enhancement. The study furthermore proposes tourism planning policy that will seek to enforce the support of community member's participation in decision making processes should be implemented. As such, the policy will present an allowance to the host community 
members of Umhlwazini to be part of tourism planning, development and implementation processes. Also the policy will permit for a planning system that will approve new tourism ventures that will be uncomplicated to manage and use for the community of Umhlwazini. Environmental Impact Assessment (EIA) method should be exploited as it provides an allowance for the host community to be a component of the pre-planning phases up until the proposed tourism development come into reality. Thus, will afford the community of Umhlwazini with a genuine opportunity to express their opinions, but also to be aware of how the anticipated developments will impact their lives and most importantly to partake on all decision making processes that involves their area of habitation and resources.

A special provision for financial support including leniency in supply chain and procurement policies needs to be established for the local community members of Umhlwazini so that they are able to enhance the footprint in tourism activities that are occurring in their area. In turn, this will have positive ripple effects on the economic sustainability of the community through employment opportunities, more business engagement from community members, and the increase in community members that are involved in tourism development. In order to bring harmony on the concern of non-participation of Umhlwazini people, it is recommended that both EKZNW and the community maximise the participation of people in decision-making. This suggests that gatherings must be held more often together with community members. The citizens of Umhlwazini should feel that decisions that are taken about tourism contribute towards their betterment. The reality is that projects are more likely to succeed and economic development happen when decisions that are taken reflect the will of community members and not that that of tourism authorities only. As stated earlier, the community members of Umhlwazini possess very partial information regarding tourism and its benefits, so, obviously their contribution to decision-making can be expected to be minimal. The concluding outcome of the study to some extent has provided a fresh perspective on how the issue of decision making in tourism can be addressed. Thus contributing immensely to the general body of literature on the subject of tourism, community consultation and decision making procedures.

\section{References}

Aref, F. \& Redzuan, M. B. (2008). Barriers to community participation toward tourism development in Shiraz, Iran. Pakistan Journal of Social Sciences, 5(9), 936-940.

Ashley, C. (2000). The impacts of tourism on rural livelihoods: Experience in Namibia. ODI Working Paper No. 128, London: ODI.

Baral, N. \& Heinen, J. T. (2007). Decentralization and people's participation ain conservation: a comparative study from the Western Trai of Nepal. International Journal of Sustainable Development and World Ecology, 14(5), 520-531.

Bryman, A. (2008). Social research methods. Oxford: Oxford University Press. Chapter 2: Research Designs and Chapter 6: The Nature of Quantitative Research.

Burns, N. \& Grove, S. K. (2003). Understanding nursing research. $3^{\text {rd }}$ ed. Philadelphia: W.B. Saunders Company.

Chok, S. \& Macbeth, J. (2007). Tourism as a tool for poverty alleviation: a critical analysis of 'pro-poor tourism' and implications for sustainability. Current Issues in Tourism, 10(2\&3), 144-164.

Cole, S. (2006). Cultural tourism, community participation and empowerment. In: Smith M. K. and Robson M. eds. Cultural tourism in a changing world: politics, participation and (re)presentation. Clevedon, UK: Channel View Publications.

Dogra, R. \& Gupta, A. (2012). Barriers to Community Participation in Tourism Development: Empirical Evidence from a Rural Destination. South Asian Journal of Tourism and Heritage, 5(1), 219-142.

Eagles, P. F. J., McCool, S. P. \& Haynes, C. D. (2002). Sustainable tourism in protected areas. Guidelines for planning and management, IUCN publications services unit, Cambridge.

Gumede, Z. S. (2009). Tourism participation in the Isimangaliso Wetland Park: perceptions, practices and prospects. Masters in Recreation and Tourism in the Department of Recreation and Tourism, University of Zululand, South Africa.

Lepp, A. (2008). Discovering self and discovering others through the Taita Discovery Centre Volunteer Tourism Programme, Kenya. In Journeys of Discovery in Volunteer Tourism, Lyon K, Wearing S (Eds). CABI Publishing: Cambridge, MA; 86-100.

Li, W. (2006). Community decision-making; Participation in development. Annals of Tourism Research, 33(1), 132-143. 
Manyara, G. \& Jones, E. (2007). Community-based tourism enterprises development in Kenya: an exploration of their potential as avenues of poverty reduction. Journal of Sustainable Tourism, 15(6), 628-644.

Mitchell, J. \& Ashley, C. (2010). Tourism and Poverty Reduction: Pathways and Prosperity; Earth scan: London, UK.

Murphree, M. (2009). The Strategic Pillars of Communal Natural Resource Management: Benefit, Empowerment and Conservation. Journal for Biodiversity Conservations, 18(10), 2551-2562.

Ngxongo, N. A. (2016). Community participation and tourism development in KwaZulu-Natal; a case study of Didima Resort and Umhlwazini. Master's Thesis, Durban University of Technology, 2016

Nykiel, R. A. (2007). Handbook of marketing research methodologies for hospitality and tourism. Illustrated. New York, NY: Routledge.

Okazaki, E. (2008). A Community-Based Tourism Model: Its Conception and Use. Journal of Sustainable Tourism, 16(5), 511-529

Phillips, R. \& .(2013 ).S ,streboRTourism, Planning, and Community Development, $1^{\text {st }}$ Edition, London, Routledge.

Scheyvens, R. (2011). Tourism and poverty. London: Routledge.

Scott, (2013). Umhlwazini: Year in the Wild, (Online), viewed 26 May 2017, from http://www.yearinthewild.com/day-1-year-in-the-wild-2013-14-the-beginning/

Scheyvens, R. (2002). Tourism for development: empowering communities. London: Pearson Prentice Hall.

Shackleton, S., Campbell, B., Wollenberg, E. \& Edmunds, D. (2002). Devolution and community-based natural resource management: creating space for local people to participate and benefit. London: Overseas Development Institute (ODI).

Smith, B. L. (2003). Public policy and public participation: engaging citizens and community in the development of public policy. Population and Public Health Branch, Atlantic Regional Office, Health Canada.

Stronza, A. \& Gordillo, J. (2008). Community views of ecotourism. Annals of Tourism Research, 35(2), 448-468.

Timothy, D., Ioannides, D., Apostolopoulos, Y. \& Gayle, D. (2002). Tour-operator hegemony: dependency, oligopoly, and sustainability in insular destinations. Island tourism and sustainable development: Caribbean, Pacific and Mediterranean experiences, 181-198.

Tosun, C. (2006). Expected nature of community participation in tourism development. Tourism Management, 27(3), 493-504.

Tosun, C. (2000). Limits to community participation in the tourism development process in developing countries, Tourism Management, 21(6), 613-633.

UKhahlamba Local Municipality. (2016). Integrated Development Plan. UKhahlamba Local Municipality. Development Planning and Environmental Consultants. Bergville.

UKhahlamba Local Municipality. (2011). Development Planning and Environmental Consultants. Bergville.

Welman, C., Kruger, F. \& Mitchell, B. (2005). Research methodology. $3^{\text {rd }}$ ed. Cape Town: Oxford.

Wilkinson, P. F. (1987). Tourism in small island nations: a fragile dependence. Leisure Studies, 6(2), 127-146.

World Tourism Organisation. (2014). World Tourism Day (WTD), Guadalajara, Mexico (online), viewed 22 July 2017, from http://wtd.unwto.org/content/about-wtd-2014-wtd2014

Zhao, W. \& Ritchie J. R. (2007). Tourism and poverty alleviation: an integrative research framework. Current Issues in Tourism, 10(2\&3), 119-143. 